\title{
Updated determination of earthquake magnitudes at the Swiss Seismological Service
}

\section{Other Conference Item}

\section{Author(s):}

Racine, Roman; Cauzzi, Carlo Virgilio (D); Clinton, John Francis (DD; Fäh, Donat; Edwards, Benjamin; Diehl, Tobias (D); Heimers, Stefan; Deichmann, Nicholas; Kästli, Philipp (D); Haslinger, Florian (D); Wiemer, Stefan (D)

\section{Publication date:}

2020-03-23

Permanent link:

https://doi.org/10.3929/ethz-b-000464292

\section{Rights / license:}

Creative Commons Attribution 4.0 International

\section{Originally published in:}

EGUsphere, https://doi.org/10.5194/egusphere-egu2020-8273 
EGU2020-8273, updated on 28 Jan 2021

https://doi.org/10.5194/egusphere-egu2020-8273

EGU General Assembly 2020

(c) Author(s) 2021. This work is distributed under

the Creative Commons Attribution 4.0 License.

\title{
Updated determination of earthquake magnitudes at the Swiss Seismological Service
}

\author{
Roman Racine ${ }^{1}$, Carlo Cauzzi ${ }^{2}$, John Clinton ${ }^{1}$, Donat Fäh ${ }^{1}$, Benjamin Edwards ${ }^{3}$, Tobias Diehl ${ }^{1}$, Stefan \\ Heimers ${ }^{1}$, Nicholas Deichmann ${ }^{1}$, Philipp Kästli ${ }^{1}$, Florian Haslinger ${ }^{1}$, and Stefan Wiemer ${ }^{1}$ \\ ${ }^{1}$ Swiss Seismological Service (SED) at ETH Zürich, Switzerland \\ ${ }^{2}$ ORFEUS and Swiss Seismological Service (SED) at ETH Zürich, Switzerland \\ ${ }^{3}$ School of Environmental Sciences, University of Liverpool, United Kingdom
}

The Swiss Seismological Service (SED; http://www.seismo.ethz.ch) at ETH Zürich is the federal agency in charge of monitoring earthquakes in Switzerland and neighboring areas, and for the assessment of seismic hazard and risk for the region. The SED seismic network largely relies on software and databases integrated in the SeisComP3 monitoring suite for waveform acquisition, automatic and manual event processing, event alerting, web infrastructure, data archiving and dissemination. Data from all digital seismic stations acquired by the SED over the last 30 years broadband (presently 230), strong-motion ( 185), short-period ( 65), permanent and temporary are homogeneously integrated in the seismic network processing tools and products. Waveform data from the Swiss National Seismic Networks are openly available through the SED website and ORFEUS EIDA / Strong-Motion (http://orfeus-eu.org/data/) data gateways. The SED earthquake catalogue is publicly available through FDSN Event web services at the SED (http://arclink.ethz.ch/fdsnws/event/1/). The Swiss seismic hazard maps are integrated in the EFEHR portal (http://www.efehr.org). The SED is updating its strategy for magnitude determination to make it fully consistent with the state-of-the-art in engineering seismology and seismic hazard studies in Switzerland, and to optimise the use of its dense seismic monitoring infrastructure. Among the planned changes are the: (a) adoption of a new ML relationship applicable in the nearsource region at epicentral distances smaller than 15-20 km; (b) inclusion of ML station corrections based on empirically observed (de)amplification with respect to the Swiss reference rock velocity model and associated predictions; (c) seamless computation of Mw based on spectral fitting of recorded FAS using a Swiss specific model. In this contribution we present and discuss the updated magnitude computations for a playback dataset of thousands of recorded earthquakes, and compare them with the current official estimates. We discuss the expected impacts of the new magnitude determination strategy on the SED event processing chain in SeisComP3, the SED catalogues and other seismological products. We welcome community feedback on our planned transition strategy. 